\title{
Carriers for Prodrug Synthesis: A Review
}

\author{
PREETI M. GANDHI*, ANURUDDHA R. CHABUKSWAR AND SWATI C. JAGDALE \\ Department of Pharmaceutical Chemistry, JSPM's Jayawantrao Sawant College of Pharmacy and Research, Hadapsar, Pune- \\ 411 028, 'Department of Pharmaceutical Chemistry, MAEER'S Maharashtra Institute of Pharmacy, Pune-411 038, India
}

\section{Gandhi et al.: Carriers for Prodrugs}

\begin{abstract}
The prodrug approach using various carriers has evolved as a significant tool in surmounting different obstacles in relation to drug formulation and targeting. Properties and selection of carriers or promoeities is a very important parameter in successful prodrug design. Carrier would change a drug's physical attributes in order to increase its fat or water solubility or to allow site-directed delivery. Though several studies have been carried out on various prodrugs, surprisingly very few reviews on different carriers, which can be used for prodrug synthesis were published to date. In this review different types of carriers, which can be used for prodrug synthesis are summarized. Examples of both marketed and investigational prodrugs using several promoieties are discussed with their advantages and future prospects. The present review is expected to be useful for scientists working in the field of drug discovery and development.
\end{abstract}

Key words: Prodrug, carriers, promoiety, polymer, amino acid, prodrug design

Prodrugs are derivatives of drug molecules that are pharmacologically inactive but require either chemical or enzymatic transformation to release the active drug in vivo in order to exert a pharmacological effect. Prodrugs have better delivery properties that surpass the parent drug molecule ${ }^{[1]}$. Prodrug concept is justified because it enables the active drug to overcome the barrier that would impede it from reaching the site of action to exert the required pharmacological activity. Some of the barriers that the prodrug approach helps to surmount are as follows, low bioavailability due to poor aqueous solubility (corticosteroids); poor permeability or absorption (ampicillin); high first pass metabolism (propranolol); metabolic instability leading to short half-life, (dopamine); poor site specificity (anticancer agents); incomplete absorption (epinephrine); unfavourable organoleptic properties (chloramphenicol); difficulties during formulation and adverse effects and toxicity ${ }^{[2-4]}$.

The prodrug approach is rapidly becoming a crucial part in the stratagem of delivery of drugs. The prodrug strategy implementation in the last $20 \mathrm{y}$ has led to a steady advancement in the biopharmaceutical, physicochemical and/or pharmacokinetic attributes of the pharmacologically active compounds. The success of the prodrug approach can be measured by examining how many prodrugs are currently on the market. Around $10 \%$ of marketed medicines can be categorized as prodrugs currently, and also that during $2008,33 \%$ of approved small molecular weight drugs were prodrugs ${ }^{[5-7]}$. The objective of this review is to provide the researchers with a compilation of which carriers would be suitable for prodrug synthesis and what would be their benefits.

\section{Classification of prodrugs:}

According to Wermuth prodrugs can be divided into two main categories, bioprecusors and carrierlinked prodrugs ${ }^{[8]}$. Bioprecursors do not have a promoiety or carrier but yield the active compound upon biotransformation. A bioprecursor prodrug is transformed chemically through hydration (for example, lactones such as some statins), reduction (for example, sulindac, platinum (IV) complexes) or oxidation (for example, dexpanthenol, nabumetone) or metabolically to the active agent ${ }^{[5,9-11]}$.

Carrier-linked prodrugs are for drugs with major drawbacks, which are linked to a nontoxic carrier or promoiety through covalent linkage to change or get

This is an open access article distributed under the terms of the Creative Commons Attribution-NonCommercial-ShareAlike 3.0 License, which allows others to remix, tweak, and build upon the work non-commercially, as long as the author is credited and the new creations are licensed under the identical terms

Accepted 05 March 2019

Revised 02 June 2018

Received 20 December 2017

Indian J Pharm Sci 2019;81(3):406-414 
rid of their undesirable physicochemical properties. These prodrugs subsequently undergo enzymatic or non-enzymatic cleavage to release the active drug moiety (fig. 1) ${ }^{[12,13]}$. The main groups of carrierlinked prodrugs are amides and esters. Other groups include carbamates, phosphates, oximes, carbonates, N-Mannich and imines bases.

Based on the essential characteristics of the carrier that is used, the carrier-linked prodrug can be classified further into, double prodrugs and mutual prodrugs. Double prodrug is derivatized further in a manner that only enzymatic conversion to prodrug is possible before the latter is able to cleave and release the active drug. A number of benzodiazepines are insoluble in water and therefore prodrugs which are water soluble are required for injections. Double prodrugs of benzodiazepines are prepared in which rate of cyclisation is influenced by the nature of amino acid carrier group (fig. 2) ${ }^{[14]}$. Macromolecules such as proteins, polymers, peptides, dextrans, polysaccharides, and cyclodextrins (CDs) can be employed as carriers in order to form macromolecular prodrugs. Site-specific prodrugs, where a carrier transports an active drug to a given targeted site.

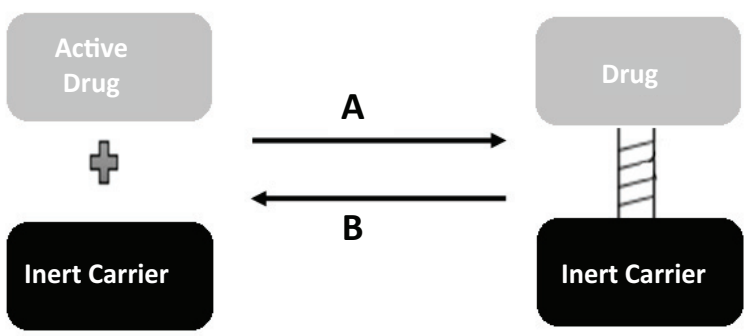

Fig. 1: Schematic representation of carrier-linked prodrug A drug $(\square)$ is linked with carrier $(\square)$ through covalent linkage (目) during chemical prodrug formation (A). Prodrug subsequently undergoes chemical or enzymatic cleavage in vivo (B) to release active drug and inert carrier

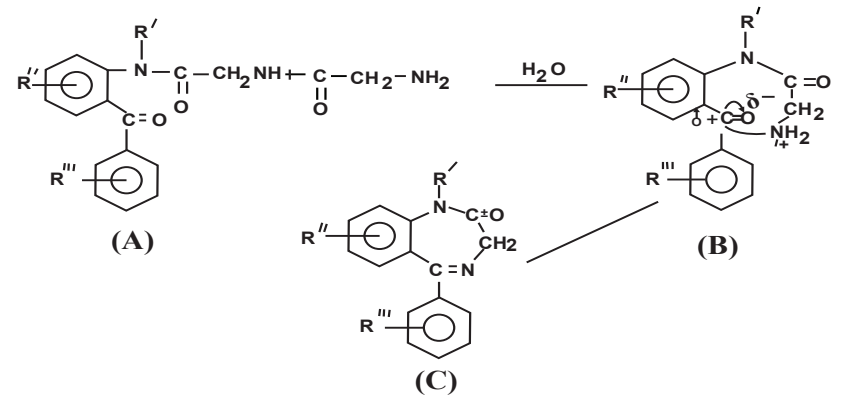

Fig. 2: Double prodrug of benzodiazepines

Double prodrug (A) of benzodiazepines gets converted to prodrug (B) after cleavage of amide bond by enzyme aminopeptidase. Prodrug (B) further undergoes cyclisation and gets converted to active drug (C). Rate of cyclisation is influenced by nature of amino acid carrier group and also the nature of $R$ ', $R$ " and $R$ "'
Mutual prodrugs are those in which, another active drug is utilized as a carrier rather than some inert molecules. It comprises of coupling two pharmacologically active agents in such a way that each active agent behaves as a promoiety for the other active agent and vice versa.

The mutual prodrug carrier selected would have additional biological action that might be absent in the parent drug or both carrier and the parent drug might have the same biological action, which ensures synergistic action or some additional benefit (e.g. sultamicilin, a mutual prodrug of ampicillin and sulbactam $)^{[15]}$. The carrier can also serve as a drug that helps to target the parent drug to a given site or cells or organ or can improve a drug's site specificity (e.g. sulfasalazine, mutual prodrug of 5-aminosalicylic acid (5-ASA) and sulfapyridine $)^{[16]}$. It can also be utilized to subdue the parent drug's side effects too (e.g. benorilate, mutual prodrug of paracetamol and aspirin $)^{[17]}$.

The benefits of carrier-linked prodrugs ${ }^{[18,19]}$ include, an increase in absorption; pain relief on the injection site; reduction of GI irritation; masking of unpleasant taste; lowering toxicity; reduction of metabolic inactivation; increasing chemical stability and prolongation or shortening of the duration of action.

\section{Criteria for carrier-linked prodrugs:}

Certain criteria need to be satisfied for a carrier-linked prodrug to be a well-designed ${ }^{[19]}$. A covalent bond binds the carrier to the drug. The prodrug needs to be inactive or rather less active compared to the parent drug. The link ought to be bioreversible. To make sure that the site of action has effective drug levels, the active form generation must occur with rapid kinetics. The carrier and prodrug released after nonenzymatic or enzymatic hydrolysis must be nontoxic. A carrier-linked prodrug bioavailability is modulated through the use of a transient moiety. In case of carrier prodrugs, lipophilicity is a subject of extensive changes of the parent molecule. The bioactivation process is exclusively hydrolytic, although at times, it is a redox system.

\section{Carriers or promoieties:}

The carrier or promoiety changes the drug's physical attributes to increase fat or water solubility or provide site-directed delivery. The choice of which carrier to use is dependent on the prodrug's purpose, the parent drug's available functional groups, the prodrug's enzymatic and chemical conversion mechanisms to parent drug, the carrier's safety, and the ease of 
manufacturing ${ }^{[20]}$. Correct choice of a carrier is the most important part of prodrug design. It should be carried out with respect to the state of the disease, the dosage, and the therapy duration. As single parent drug can be derivatized to several prodrugs, this change is due only to the change in nature of promoiety. This difference in the promoiety varies the cleavage of drug and promoiety bond ${ }^{[21]}$.

\section{Criteria for carriers:}

In an ideal situation, the carrier should not have intrinsic toxicity. The carrier should also be nonantigenic and non-immunogenic, and should not accumulate in the body. Instead, the carrier should have satisfactory functional groups for adequate loading capacity and drug attachment. It should also be relatively easy to produce at a low cost. A carrier must remain stable under prodrug administration conditions, chemical manipulation and autoclaving. It should undergo biodegradation to inactive metabolites. Its characterization should be easy, and it needs to mask the liganded drug's activity until the active agent released at the desired action site. The carrier is expected to have some biological activity of its own in relation to a mutual prodrug approach ${ }^{[5,7,11,22]}$.

\section{Lipids as prodrug carriers:}

Lipidic prodrugs, also known as drug-lipid conjugates, have the lipid moiety covalently bound to a drug. Drug-lipid conjugates are prepared so as to exploit the advantage of the metabolic pathway of the lipid biochemistry, and thus allow for targeting of organs or overcome delivery problems. Pharmacological half-life and pharmacokinetics of the drug can be improved by using lipid carriers, thus allowing for reduced dosing frequency. Lipids have other advantages such as an increase in absorption through intestines in regards to oral drug absorption and to the central nervous system for brain delivery. In addition, drug targeting may be enhanced using the lipid delivery systems. To target the liver, lipids are bound with endogenous proteins in the blood, which carries the lipids to the organ ${ }^{[23,24]}$.

Various natural lipid carriers are commonly used in the design of lipid prodrugs, including glycerides, fatty acids, and phospholipids. In designing the fatty acid-linked conjugates, the drugs are linked either to the $\omega$-position at the end of the carbon chain or to the free carboxylate group (fig. 3a). In case of conjugation to a carboxylate group, a drug containing an amino group or alcohol is linked to the fatty acid, which results in an ester or amide-linked conjugate, respectively. These conjugation strategies generally involve the use of an activating agent, such as $\mathrm{N}^{\prime} \mathrm{N}^{\prime}$ carbonyldiimidazole or carbodiimide, to convert the poor $-\mathrm{OH}$ leaving group to a better one, followed by the addition of an amine- or alcohol-containing drug $^{[25,26]}$. This approach is the most common method of linking fatty acids and has been utilized for many parent drugs including non-steroidal antiinflammatory drugs (NSAIDs, ketorolac) ${ }^{[27]}$, angiotensinconverting-enzyme inhibitors (enalapril) ${ }^{[28]}$, nucleosides (zidovudine) ${ }^{[29]}$ and testosterone ${ }^{[30]}$. Conjugation to the $\omega$-position is preferable in cases where increased albumin binding and cell membrane transporter properties are preferred. For this method, an $\omega$-modified fatty acid, such as amino ${ }^{[31]}$ or thiol ${ }^{[32]}$ analogue, is utilized to link to the parent drug.

Similar to fatty acids, glyceride prodrugs also take advantage of natural biosynthetic pathways. Glyceride conjugates are linked to orally administered drugs in order to reduce gastric damage of certain drugs (NSAIDs including aspirin ${ }^{[33]}$, indomethacin ${ }^{[34]}$, ibuprofen ${ }^{[35]}$ ) by preventing their release in the stomach, to reduce enzymatic degradation in the intestines, to target the lymphatic route, or to enhance their delivery through the blood-brain barrier ${ }^{[36]}$. In this approach, drugs containing a carboxylate group are linked to the glyceride via an ester bond (fig. 3b).

The conjugation chemistry is also similar to fatty acid conjugation, involving the use of an activating agent or acid halide (chloride) derivative. In phospholipidlinked prodrugs, the drugs are either attached to the glycerol backbone or to the phosphate group (fig. 3c). Drugs that are linked to the phosphate group
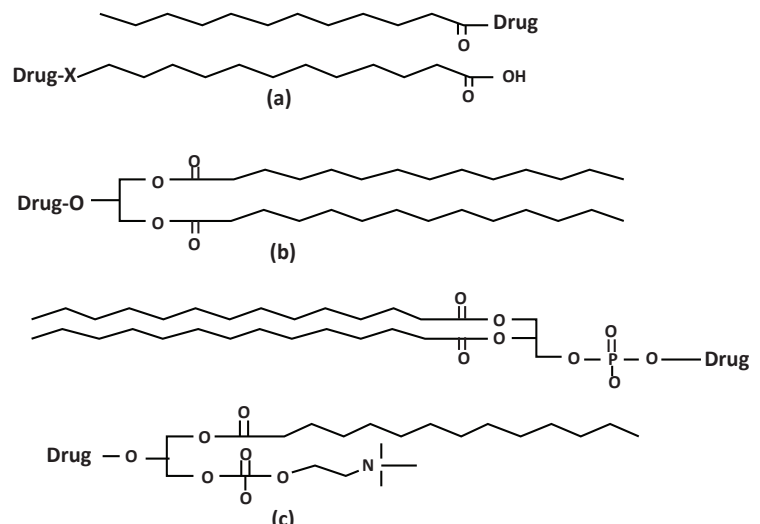

Fig. 3: Types of lipidic carriers: fatty acids, glycerides and phospholipids.

(a) Drug attached to fatty acid $(X=O, N H)$; (b) drug attached to glyceride; (c) drug attached to phospholipid 
are generally antiviral nucleoside analogues. These prodrugs take advantage of drug release inside the cell in a monophosphate form, bypassing possible deficiencies in nucleoside kinase activity. Drugs attached to the glycerol backbone utilize the natural absorption pathway for phospholipids to cross the intestinal lumen or blood-brain barrier ${ }^{[23]}$.

\section{Amino acids as prodrug carriers:}

Amino acids do have proven record of being successfully used as promoieties in synthesis of prodrugs. In recent times, a hot field in regards to drug delivery research has concentrated on developing amino acid prodrugs for different active transporter targeted delivery goals ${ }^{[37]}$. Most of amino acid prodrugs are either esters or amides, in which amine or carboxylic group of amino acid is attached to hydroxyl, amine or carboxyl group of drug moiety. Amino acids are biocompatible and easily ionisable. The amino acid prodrugs improve oral delivery of drugs, which have poor permeability and solubility. When an amino acid is introduced, be it a derivative or natural, to a parent drug, it normally rises the solubility in water by multiplier magnitudes via an ammonium cation or an ionized carboxylate anion.

In addition, numerous transporters required for absorbing oligopeptides and amino acids are expressed in the epithelial cells of the intestinal brush-border membranes and have been discovered to play a substantial role in absorbing various amino acid prodrugs ${ }^{[38]}$. For instance, the enhanced oral bioavailability of valganciclovir and valacyclovir, amino acid ester prodrugs of ganciclovir and acyclovir, respectively, are ascribed to their enhanced intestinal transport through the $\mathrm{H}+$-coupled peptide transporter 1 (PEPT1 $)^{[39,40]}$. In recent times, prodrugs of amino acid have ensured controlled drug release in the kind of lisdexamfetamine dimesylate, which is a L-lysine amino acid amide prodrug of D-amphetamine ${ }^{[41]}$.

Benefits of amino acids as promoieties ${ }^{[38,42]}$ include, large structural diversity; they are normal dietary constituents and are nontoxic in moderate doses as compared to other promoieties; a broad range of functional groups like hydroxyl, amine, or carboxylic acid group, which can be attached to parent drug; wellestablished prodrug chemistry; commercial availability; fewer safety concerns; substrates for various different intestinal influx transporters; they have gastroprotective action; the availability of amino acid prodrugs those are commercially successful; utilized for the improvement of pharmaceutical attributes of difficult compounds or marketed drugs.

All $\alpha$-amino acids contain a chiral $\alpha$-carbon with the exception of glycine, and are available in two optical isomers, D- and L-form. The L-form exists naturally. As such, the prodrugs prepared by using these amino acids are normally activated by enzymes that occur naturally. The L- and D-amino acid prodrugs have similar physicochemical attributes; however, the latter is stable against hydrolysis due to enzymes that occur naturally. This amino acid characteristic is frequently used by medicinal chemists to create stable prodrugs of amino acid. Furthermore, the large arrays of di-/tripeptides and synthetic amino acids like D-amino acids, homo amino acids, beta-homo amino acids, N-methyl amino acids, $\alpha$-methyl amino acids are commercially available as promoieties for medicinal chemists in addition to natural amino acids ${ }^{[43]}$.

When amino acids are promoieties, they offer the largest expanse and structural diversity of physicochemical properties. By selection of the proper amino acid, polarity, solubility profile and acid base properties of a given drug molecule can be altered. Few examples of produgs that are reported using amino acids as promoieties and the advantage achieved thereof are given in Table $1^{[44-49]}$.

\section{Polysaccharides as prodrug carriers:}

Polysaccharides are used as promoieties specifically for colon targeting drug delivery. Various polysaccharides, such as cyclodextrin, dextran, pectin, chitosan and chondroitin are conjugated with drugs. Chondroitin sulphate, a copolymer of D-glucuronic acid and sulphated $\mathrm{N}$ acetyl D-galactosamine, is an important structural component in connective tissue and cartilage. It can be used as a good candidate for colon-targeted drug carriers. CDs belong to the family of oligosaccharides. They are obtained by enzymatic degradation of starch. CDs are nontoxic and thought to be one of the most suitable promoieties to reduce ulcerogenic tendency of drugs.

Dextran has excellent physicochemical properties, physiological response and unique pharmacokinetic profile. It contains large number of carbohydrate hydroxyl groups available, which can be linked to drug. Even though this limits the number of drugs that might be directly liganded to the matrix using application of spacer arm technique, which links drugs possessing 


\begin{tabular}{|c|c|c|c|}
\hline Amino acids used as carriers & Conjugation with drug & Advantage & Reference \\
\hline Valine & Saquinavir, indinavir & $\begin{array}{l}\text { Improved pharmacological and } \\
\text { pharmacokinetic profile }\end{array}$ & 44 \\
\hline L-Valine & Acyclovir, zidovudine & Enhanced cellular uptake & 45 \\
\hline L-alanine and histidine & Aceclofenac & Reduced gastrointestinal side effects & 46 \\
\hline $\begin{array}{l}\text { Glycine, phenylalanine, tryptophan, } \\
\text { L-isoleucine, L-alanine, L-valine, L-aspartic } \\
\text { acid L-glutamic acid }\end{array}$ & Ketorolac & $\begin{array}{l}\text { Controlled release and reduced } \\
\text { gastrointestinal side effects }\end{array}$ & 42 \\
\hline L-tryptophan, histidine, DL-alanine & Flurbiprofen & Reduced gastrointestinal side effects & 47 \\
\hline $\begin{array}{l}\text { Phenylalanine, valine and proline } \\
\text { Glycine, alanine, lysine, }\end{array}$ & Floxuridine & $\begin{array}{l}\text { Good solution stability and fast } \\
\text { enzymatic conversion rates }\end{array}$ & 48 \\
\hline leucine, phenylalanine & Dapsone & Improved water solubility & 49 \\
\hline
\end{tabular}

diverse functional groups to dextran ${ }^{[50]}$. Literature revealed that in most polymeric prodrugs, the drug is connected to polymeric carrier by a chemical linkage. Dextran was investigated as a macromolecular carrier for delivering drugs and also demonstrated that it is useful to target therapeutic agents to the liver. The examples of polysaccharides as prodrug carriers with their advantages are given in Table $2^{[51-55]}$.

\section{Phytophenols as prodrug carriers:}

Traditionally phytophenols are used for their medicinal as well as flavouring properties, with well-documented safety profiles. Phytophenols can be linked to drugs containing carboxylic group via an ester bond. These are used as prodrug carriers to combine antiinflammatory and antioxidant properties. Naturally occurring phenolic antioxidants are thymol, guaiacol and eugenol whereas menthol is alcoholic compound. Menthol, thymol, eugenol, guaiacol, vanillin, umbelliferone (Table 3$)^{[56-58]}$ are the promoieties used in prodrug synthesis. They show antioxidant as well as gastroprotective properties.

\section{Alcohols as prodrug carriers:}

Esters dominate research due to their ideal characteristics that exhibit sufficient chemical stability in vitro and their ability to function as esterase substrates for in vivo regeneration ${ }^{[59]}$. Alcohols form ester bonds with carboxylic groups of drug moiety. N-propyl, iso-butyl, iso-propyl, t-butyl, benzyl, cyclopentyl and cyclohexyl alcohols (Table 4) ${ }^{[60,61]}$ are alcohols used as promoieties in synthesis of ester prodrugs. Iodomethyl pivalate and 2-bromo ethyl acetate are also used.

\section{Amines as prodrug carriers:}

For the synthesis of amide prodrugs various amines like propylamine, diethylamine, cyclohexyl amine, 2-amino ethyl amine, 2-hydroxyl ethyl amine, ethylenediamine, benzathine and cysteamine (Table 5) ${ }^{[62-64]}$ are used as carriers. These form amide bonds with carboxylic groups of drug moiety.

\section{Polymers as prodrug carriers:}

Within the last $20 \mathrm{y}$, scientists concentrated on creating drug delivery systems that were site specific and various polymers showed promising outcomes. A drug and polymer conjugation forms the polymeric prodrug. In 1975, Ringsdorf for the first time formulated a rational model (fig. 4) of a polymeric prodrug. Ringsdorf was first to recognize that if biologists and polymer chemists work together polymeric prodrugs with immense potential can be evolved ${ }^{[65]}$. The suggested model is made up of majorly five elements, the drug, the targeting group, the polymeric backbone, the solubilizing agent, and the spacer. The carrier is either biodegradable or an inert polymer. The spacer controls the site and the rate of active drug release from the conjugate ${ }^{[66]}$. The drug and the polymer must be covalently bonded together. The drug must stay linked to the polymer until the macromolecule reaches to the desired action site.

Three criteria are used as basis to select the drug to be used in this system, first, due to restriction on the quantity of drug that can be administered, only a potent drug should be used. Second, the drug should possess proper functional group so as to bind successfully to polymer backbone directly or through spacer molecule. Third, the drug has to be sufficiently stable. Until drug gets released at the desired site it must not be excreted in the conjugate form ${ }^{[67]}$. Polymer like polyethylene glycol (PEG) can be attached to the hydroxyl or amine group of the drug via spacers and linked to the spacer via an ester, amide, carbonate, or carbamate bond that undergoes either chemical or enzymatic cleavage in the bioconversion process. 


\section{Classification of polymers:}

Below is a classification of some important polymers used for bioconjugation based on their origin, synthetic polymers- PEG, divinylethermaleic anhydride/acid copolymer, polyethylenimine or polyaziridine and vinyl polymers- a) N-(2-hydroxypropyl) methacrylamide b) poly(styrene-co-maleic acid/anhydride). Natural polymers- dextran, chitosan, proteins. Pseudosynthetic

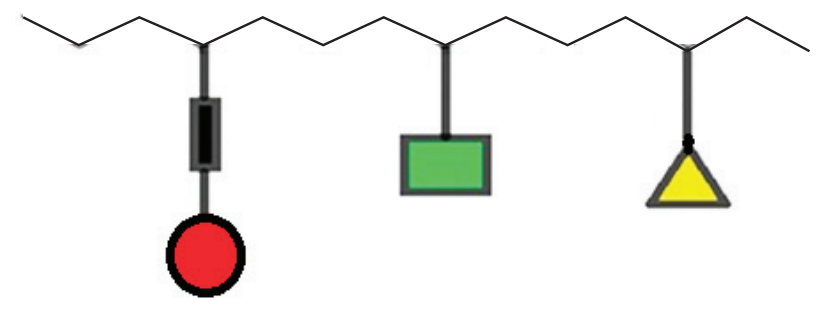

Fig. 4: Ringsdorf's model of polymeric prodrug Five elements of Ringsdorf's model: the drug $(\mathcal{O})$, the targeting moiety $(\Delta)$, the polymeric backbone $(\curvearrowright)$, the solubilizing agent $(\square)$ and the cleavable spacer ( $(1)$ polymers- synthetic poly( $\alpha$-amino acids) like poly(Lglutamic acid), poly(L-lysine), poly(N-hydroxyalkyl) glutamines) and polyglycolic or polyglycolide acid. Proper drug and polymer candidate must be selected while designing the polymeric conjugates. Table 6 shows few examples of polymeric prodrugs available in the market.

\section{Requirements for choosing polymers as drug carriers:}

The availability of suitable functional groups such as $-\mathrm{OH},-\mathrm{COOH},-\mathrm{NH} 2$, or $-\mathrm{SH}$ to covalently bind with drugs, biocompatible, non-immunogenic and nontoxic, biodegradable, molecular weight low enough to limit renal excretion, availability, reproducible manufacture, ease of administration to patients, hydrophilic to ensure aqueous solubility, low polydispersity and final conjugates should have a satisfactory homogeneity ${ }^{[68]}$. Prodrugs are increasingly becoming an integral

TABLE 2: POLYSACCHARIDE PRODRUGS

\begin{tabular}{lccc}
\hline Polysaccharides used as carriers & Conjugation with drug & Advantage & Reference \\
\hline Cyclodextrin & Mefenamic acid & Reduced ulcerogenic potential & 51 \\
Dextran & Flurbiprofen and suprofen & Improved analgesic and antipyretic effect & 52 \\
Chitosan glucosamine & with low ulcerogenic potential & 53 \\
Dextran & Metronidazole & Colon-targeted drug delivery & 54 \\
Dextran & Valproic acid & Reduced hepatotoxicity and ulcerogenicity & 54 \\
\hline
\end{tabular}

\section{TABLE 3: PHYTOPHENOLIC PRODRUGS}

\begin{tabular}{lccc}
\hline Phytophenols used as carriers & Conjugation with drug & Advantage & Reference \\
\hline Guaiacol, eugenol, thymol, & Diclofenac & Reduced ulcerogenic potential & 56 \\
Vanillin, umbelliferone, menthol. & Ibuprofen & $\begin{array}{c}\text { Synergistic analgesic action and } \\
\text { reduced gastrointestinal toxicity }\end{array}$ & 57 \\
Menthol, thymol, eugenol & Mefenamic acid & $\begin{array}{c}\text { Synergistic antiinflammatory activity } \\
\text { and less toxicity }\end{array}$ & 58 \\
Guaiacol & & 5
\end{tabular}

TABLE 4: ESTER PRODRUGS

\begin{tabular}{lccc}
\hline Alcohols used as carriers & Conjugation with drug & Advantage & Reference \\
\hline $\begin{array}{l}\text { Cyclopentyl alcohol, cyclohexanol, iso-butyl alcohol, } \\
\text { t-butyl alcohol }\end{array}$ & Flurbiprofen & $\begin{array}{c}\text { Decreased gastrointestinal side } \\
\text { effects }\end{array}$ & 60 \\
lodomethyl pivalate and 2- bromo ethyl acetate & Indomethacin & $\begin{array}{c}\text { Reduced gastrointestinal side } \\
\text { effects }\end{array}$ & 61 \\
\hline
\end{tabular}

\section{TABLE 5: AMIDE PRODRUGS}

\begin{tabular}{|c|c|c|c|}
\hline Amines used as carriers & Conjugation with drug & Advantage & Reference \\
\hline Ethylenediamine and benzathine conjugate & Ibuprofen & $\begin{array}{l}\text { Reduced gastrointestinal side effects } \\
\text { and improved analgesic activity }\end{array}$ & 62 \\
\hline $\begin{array}{l}\text { Propylamine, diethylamine, cyclohexyl amine, } \\
\text { 2-amino ethyl amine, 2-hydroxyl ethyl amine }\end{array}$ & Ketoprofen & $\begin{array}{l}\text { Reduced gastrointestinal side effects } \\
\text { and improved analgesic activity }\end{array}$ & 63 \\
\hline Cysteamine & $\begin{array}{l}\text { Ibuprofen and } \\
\text { Indomethacin }\end{array}$ & $\begin{array}{l}\text { Antioxidant activity and lower } \\
\text { ulcerogenic potential }\end{array}$ & 64 \\
\hline Heterocyclic amide & Ibuprofen & $\begin{array}{l}\text { Improved analgesic activity, lower } \\
\text { ulcerogenic potential }\end{array}$ & 64 \\
\hline
\end{tabular}




\begin{tabular}{lc}
\hline Conjugate & Indication \\
\hline PEG-adenosine deaminase (Adagen) & SCID Syndrome \\
PEG-asparaginase (Oncaspar) & Acute Lymphoblastic Leukemia \\
Linear PEG Interferon $a-2 b$ (PEG-Intron) & Hepatitis C, multiple sclerosis and HIV-AIDS \\
PEG-growth hormone receptor antagonist & Acromegaly \\
PEG-G-CSF (Pegfilgrastim, Neulasta) & Prevention of neutropenia associated with cancer chemotherapy \\
Branched PEG-antiVEGF aptamer & Muscular degeneration (age related) \\
PEG-antiTNF-Fab & Crohn's disease and Rheumatoid arthritis \\
SMANCS (Zinostatin stimalamer) & Hepatocellular carcinoma \\
\hline
\end{tabular}

SCID is severe combined immunodeficiency disease, AIDS is acquired immune deficiency syndrome, PEG-G-CSF is pegylated granulocyte colony stimulating factor, VEGF stands for vascular endothelial growth factor and TNF is tumor necrosis factor

component of the drug discovery stratagem. The rising percentage of approved new drug entities which are in fact, prodrugs, is a clear indication of their importance. Proper selection of a carrier is the most important part of prodrug design and synthesis. Selection of promoeity in prodrug research should be done wisely as it will determine the regeneration of active drug in vivo and also the promoeity itself should be nontoxic and excreted soon. The authors hope that the current review provides enough impetus to research different carriers for synthesis of prodrugs to succeed in delivery despite the challenges currently posed by complex molecules that are under development.

\section{REFERENCES}

1. Rautio J, Kumpulainen H, Heimbach T, Oliyai R, Oh D, Järvinen T, et al. Prodrugs: design and clinical applications. Nat Rev Drug Discov 2008;7(3):255-70.

2. $\mathrm{Wu} \mathrm{KM}$. A New Classification of Prodrugs: Regulatory Perspectives. Pharmaceuticals (Basel) 2009;2(3):77-81.

3. Buxton ILO. Pharmacokinetics and Pharm $\alpha \chi 0 \delta \psi v \alpha \mu \imath \chi \sigma: T \eta \varepsilon$

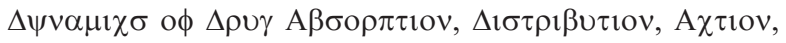

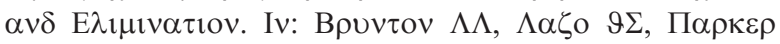

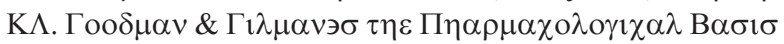

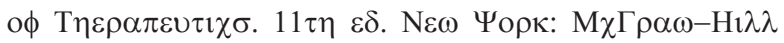

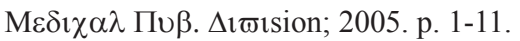

4. Goldstein A, Aronow L, Kalman SM. Principles of Drug Action: the basis of pharmacology. 2nd ed. NJ, USA: John Wiley \& Sons; Hoboken; 1974.

5. Zawilska JB, Wojcieszak J, Olejniczak AB. Prodrugs: A challenge for the drug development. Pharmacol Rep 2013;65:1-14.

6. Stella VJ. Prodrugs: Some thoughts and current issues. J Pharm Sci 2010;99:4755-65.

7. Huttunen KM, Raunio H, Rautio J. Prodrugs-from Serendipity to Rational Design. Pharmacol Rev 2011;63:750-71.

8. Wermuth CG. Designing Prodrugs and Bioprecursors. In: Drug Design: Fact or Fantasy? Jolles G, Woolridge KRH, editors. London: Academic Press; 1984, p.47-72.

9. Kokil GR, Rewatkar PV. Bioprecursor prodrugs: molecular modification of the active principle. Mini Rev Med Chem 2010;10:1316-30.

10. Shi Y, Liu SA, Kerwood DJ, Goodisman J, Dabrowiak JC. Pt (IV) complexes as prodrugs for cisplatin. J Inorg Biochem
2012;107:6-14.

11. Bhosle D, Bharambe S, Gairola N, Dhaneshwar SS. Mutual Prodrug Concept: Fundamentals and Applications. Indian J Pharm Sci 2006;68:286-94.

12. Sinkula AA. Prodrugs, protective groups and the medicinal chemist. In: Medicinal Chemistry. Mathieu J, editor. Vol. 5. Amsterdam: Elsevier; 1977. p.125.

13. Wermuth CG. Natural Prodrugs as Medicinal Agents. Stuttgart: Hippokrates Verlag; 1981.

14. Pandeya SN, Dimmock JR. An Introduction to Drug Design. 1st ed. New Delhi: New Age International (P) Limited, Publishers; 1997.

15. Arthur ER, Girard D, Haskell SL. Pharmacokinetics of sultamicillin in Mice, Rats, and Dogs. Antimicrob Agents Chemother 1984;25(5):599-602.

16. Nagpal D, Singh R, Gairola N, Bodhankar S, Dhaneshwar S. Mutual azo prodrug of 5-aminosalicylic acid for colon targeted drug delivery: synthesis, kinetic studies and pharmacological evaluation. Indian J Pharm Sci 2006;68:171-8.

17. Williams FM, Moore U, Seymour RA, Mutch EM. Benorylate hydrolysis by human plasma and human liver. $\mathrm{Br}$ J Clin Pharmacol 1989;28:703-8.

18. Shirke S, Shewale S, Satpute M. Prodrug design: an overview. Int J Pharm Chem Biol Sci 2015;5(1):1232-41.

19. Stella V. Prodrugs as a Novel Drug Delivery System. Washington DC: American Chemical Society; 1975.

20. Redasani VK. Prodrugs as Emerging Tool for Increasing Safety Profile of Existing Drugs. Res Reviews J Chem 2015;4(3):23.

21. Redasani VK, Bari S. Prodrug Design Perspectives, Approaches and Applications in Medicinal Chemistry. 1st ed. Cambridge, Massachusetts, United States: Academic Press; 2015.

22. Srinivas NR. The rationality for using prodrug approach in drug discovery programs for new xenobiotics: opportunities and challenges. Eur J Drug Metab Pharmacokinet 2011;36:49-59.

23. Zaro JL. Lipid-Based Carriers for Prodrugs to Enhance Delivery. AAPS J 2015;1(1):83-92.

24. Lambert DM. Rationale and applications of lipids as prodrug carriers. Eur J Pharm Sci 2000;11(2):S15-27.

25. Christie WW. Advances in lipid methodology. Dundee: Oily Press; 1993.

26. Taylor MD. Improved passive oral delivery via prodrugs. Adv Drug Deliv Rev 1996;19(2):131-48.

27. Bhandari KH, Newa M, Yoon SI, Kim JS, Jang KY, Kim JA, et al. Evaluation of physicochemical properties, skin permeation and accumulation profiles of ketorolac fatty ester prodrugs. Biol Pharm Bull 2007;30:2211-6. 
28. Friedman D, Amidon GL. Passive and carrier-mediated intestinal absorption components of two angiotensin converting enzyme (ACE) inhibitor prodrugs in rats: enalapril and fosinopril. Pharm Res 1989;6:1043-7.

29. Bibby DC, Charman WN, Charman SA, Iskander MN, Porter $\mathrm{CJH}$. Synthesis and evaluation of $5^{\prime}$ alkyl ester prodrugs of zidovudine for directed lymphatic delivery. Int $\mathrm{J}$ Pharm 1996;144(1):61-70.

30. Leblanc GA, Gooding MP, Sternberg RM. Testosterone-Fatty Acid esterification: a unique target for the endocrine toxicity of tributyltin to gastropods. Integr Comp Biol 2005;45(1):81-7.

31. Charbon V, Latour I, Lambert DM, Buc-Calderon P, Neuvens L, De Keyser JL, et al. Targeting of drug to the hepatocytes by fatty acids. Influence of the carrier (albumin or galactosylated albumin) on the fate of the fatty acids and their analogs. Pharm Res 1996;13(1):27-31.

32. Sasson K, Marcus Y, Lev-Goldman V, Rubinraut S, Fridkin M, Shechter Y. Engineering prolonged-acting prodrugs employing an albumin-binding probe that undergoes slow hydrolysis at physiological conditions. J Control Release 2010;142(2):214-20.

33. Paris GY, Garmaise DL, Cimon DG, Swett L, Carter GW, Young P. Glycerides as prodrugs. 2. 1,3-Dialkanoyl-2-(2methyl-4-oxo1,3-benzodioxan-2-yl)glycerides (cyclic aspirin triglycerides) as antiinflammatory agents. J Med Chem 1980;23(1):79-82.

34. Paris GY, Garmaise DL, Cimon DG, Swett L, Carter GW, Young P. Glycerides as prodrugs.3.Synthesis and antiinflammatory activity of [1-(p-chlorobenzoyl)-5-methoxy-2-methylindole3 -acetyl]glycerides (indomethacin glycerides). J Med Chem 1980;23(1):9-13.

35. Cullen E. Novel anti-inflammatory agents. J Pharm Sci 1984;73(5):579-89.

36. Scriba GK, Lambert DM. Bioavailability of phenytoin and anticonvulsant activity after oral administration of phenytoinbis-hydroxyisobutyrate to rats. Pharm Res 1997;14(2):251-3.

37. Sutera FM, De Caro V, Giannola LI. Small endogenous molecules as moiety to improve targeting of CNS drugs. Expert Opin Drug Deliv 2017;14(1):93-107.

38. Vig BS, Huttunen KM, Laine K, Rautio J. Amino acids as promoieties in prodrug design and development. Adv Drug Del Rev 2013;65:1370-85.

39. Balimane PV, Tamai I, Guo A, Nakanishi T, Kitada H, Leibach $\mathrm{FH}$, et al. Direct evidence for peptide transporter (PepT1)mediated uptake of a nonpeptide prodrug, valacyclovir. Biochem Biophys Res Commun 1998;250(2):246-51.

40. Sugawara M, Huang W, Fei YJ, Leibach FH, Ganapathy V, Ganapathy ME. Transport of valganciclovir, a ganciclovir prodrug, via peptide transporters PEPT1 and PEPT2. J Pharm Sci 2000;89(6):781-9.

41. Pennick M. Absorption of lisdexamfetamine dimesylate and its enzymatic conversion to D-amphetamine. Neuropsychiatr Dis Treat 2010;6:317-27.

42. Mishra A, Veerasamy R, Jain PK, Dixit VK, Agrawal RK. Synthesis, Characterization and pharmacological evaluation of amide prodrugs of ketorolac. Eur J Med Chem 2008;43:2464-72.

43. Ma JS. Unnatural amino acids in drug discovery. Chim Oggi 2003;21:65-68.

44. Roche D, Greiner J, Aubertin AM, Vierling P. Synthesis and in vitro Biological Evaluation of Valine-Containing Prodrugs Derived From Clinically Used HIV- Protease Inhibitors. Eur J Med Chem 2008;43:1506-18.

45. Han HK, Oh DM, Amidon GL. Cellular uptake mechanism of amino acid ester prodrugs in Caco-2/hPEPT1 cells overexpressing a human peptide transporter. Pharm Res 1998;15(9):1382-6.

46. Ashok Kumar CK. Design, Synthesis, hydrolysis kinetics and pharmacodynamic profiles of histidine and alanine conjugates of aceclofenac. Acta Pharm 2010;60:99-109.

47. Gairola N, Nagpal D, Dhaneshwar SS, Dhaneshwar SR, Chaturvedi SC. Synthesis, hydrolysis kinetics and pharmacodynamic profile of novel prodrugs of flurbiprofen. Indian J Pharm Sci 2005;67:369-73.

48. Vig BS, Lorenzi PJ, Mittal S, Landowski CP, Shin HC, Mosberg HI, et al. Amino acid ester prodrugs of floxuridine: synthesis and effects of structure, stereochemistry, and site of esterification on the rate of hydrolysis. Pharm Res 2003;20:1381-8.

49. Pochopin NL, Charman WN, Stella VJ. Amino acid derivatives of dapsone as water-soluble prodrugs. Int J Pharm 1995;121(2):157-67.

50. Dhaneshwar SS, Kandpal M, Gairola N, Kadam SS. Dextran: A promising macromolecular drug carrier. Indian J Pharm Sci 2006,68 (6):705-14.

51. Dev S, Mhaske DV, Kadam SS. Dhaneshwar SR. Synthesis and Pharmacological Evaluation of Cyclodextrin Conjugate Prodrug of Mefenamic Acid. Indian J Pharm Sci 2007;69:69-72.

52. Shrivastava SK, Jain DK, Shrivastava PK, Trivedi P. Flurbiprofen and Suprofen- Dextran Conjugates: Synthesis, Characterization and Biological Evaluation. Trop J Pharm Res 2009;8:221-9.

53. Mura C, Valenti D, Floris C, Sanna R, Luca MA, Fadda AM, et al. Metronidazole Prodrugs: Synthesis, Physicochemical Properties, Stability and ex vivo release studies. Eur J Med Chem 2011;46:4142-50.

54. Praveen B, Shrivastava P, Shrivastava SK. In vitro Release and Pharmacological Study of Synthesized Valproic AcidDextran Conjugate. Acta Pharm Sci 2009;51:169-76.

55. Tu J, Zhong S, Li P. Studies on acyclovir-dextran conjugate: synthesis and pharmacokinetics. Drug Dev Ind Pharm 2004;30(9):959-65.

56. Manon B, Sharma PD. Design, synthesis and evaluation of Diclofenac antioxidant mutual prodrugs as safer NSAIDs. Indian J Chem 2009;48B:1279-87.

57. Zhao X, Chen D, Gao P, Ding P, Li K. Synthesis of ibuprofen Eugenol ester and its microemulsion formulation for parenteral delivery. Chem Pharm Bull 2005;53:1246-50.

58. Tantishaiyakul V, Pinsuwan S, Kasiwong S, Phadoonsongsombut N, Kaewnopparat S, Kaewnopparat N, et al. Characterization of Mefenamic Acid- Glucinol Ester: Stability and Transport Across Caco-2 Cell Monolayers. Pharm Res 2002;19:1013-18.

59. Sriram D, Yogeeswari P, Srichakravarthy N, Bal TR. Synthesis of Stavudine amino acid ester prodrugs with broad-spectrum chemotherapeutic properties for the effective treatment of HIV/AIDS. Bioorg and Med Chem Lett 2004;10:1085-7.

60. Mohan R, Ramma CS. Ester prodrugs of flurbiprofen: Synthesis, plasma hydrolysis and gastrointestinal toxicity. Indian J Chem 2007;46B:1164-8.

61. Bandgar BP, Sarangdhar RJ, Viswakarma S, Ahamed FA. 
Synthesis and Biological Evaluation of Orally Active Prodrugs of Indomethacin. J Med Chem 2011;54:1191-201.

62. Chatterjee NR, Kulkarni AA, Ghulekar SP. Synthesis, pharmacological activity and hydrolytic behavior of ethylenediamine and benzathine of ibuprofen. Eur J Med Chem 2008;43:2819-23.

63. Zovko M, Zorc B, Takac MJM, Metelko B, Novak P. The novel ketoprofenamides: Synthesis and spectroscopic characterization. Croatica Chem Acta 2003;76:335-41.

64. Teresa M, Congiu C, Onnis V, Morelli M, Cauli O. Synthesis of ibuprofen heterocyclic amides and investigation of their analgesic and toxicological properties. Eur J Med Chem 2003;38:513-8.

65. Rohini, Agrawal N, Joseph A, Mukerji A. Polymeric Prodrugs:
Recent Achievements and General Strategies. J Antivir Antiretrovir 2013;S15:2-12.

66. Etrych T, Chytil P, Jelinkova M, Rihova B, Ulbrich K. Synthesis of HPMA copolymers containing doxorubicin bound via a hydrazone linkage: Effect of spacer on drug release and in vitro cytotoxicity. Macromol Biosci 2002;2:43-52.

67. Duncan R. Sustained and controlled drug delivery systems. In: Robinson JR, Lee VHL, editors. Controlled drug delivery: fundamentals and applications. New York: Marcel Dekker; 1987. p.581-621.

68. Ulbrich K, Subr V, Strohalm J, Plocová D, Jelínková M, Ríhová B. Polymeric drugs based on conjugates of synthetic and natural macromolecules. I. Synthesis and physicochemical characterization. J Control Release 2000;64:63-79. 